\title{
Initial Mechanical Stabilization of Conventional Glass Ionomer Cements with Different Active Principles
}

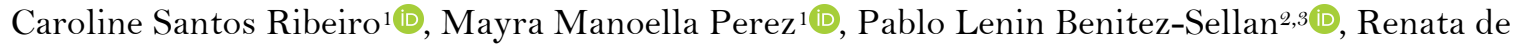

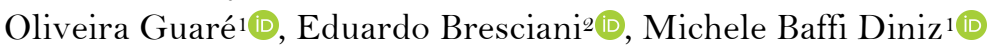

${ }^{1}$ Postgraduate Program in Dentistry, Cruzeiro do Sul University, São Paulo, SP, Brazil.

${ }^{2}$ Department of Restorative Dentistry, Institute of Science and Technology, São Paulo State University, São José dos Campos, SP, Brazil.

${ }^{3}$ School of Dentistry, Espiritu Santo University, Samborondon, Guayas, Ecuador.

Correspondence: Prof. Dr. Michele Baffi Diniz, Postgraduate Program in Dentistry, Cruzeiro do Sul University, Rua Galvão Bueno, 868, Liberdade, São Paulo, SP, Brazil. 01506-000. E-mail: mibdiniz@hotmail.com

Academic Editor: Alessandro Leite Cavalcanti

Received: 17 May 2020 / Review: 05 July 2020 / Accepted: 26 August 2020

How to cite: Ribeiro CS, Perez MM, Benitez-Sellan PL, Guaré RO, Bresciani E, Diniz MB. Initial mechanical stabilization of conventional glass ionomer cements with different active principles. Pesqui Bras Odontopediatria Clín Integr. 2021; 21:e0096. https://doi.org/10.1590/pboci.2021.040

\begin{abstract}
Objective: To determine the initial mechanical stabilization of conventional glass ionomer cements (GICs) indicated for the atraumatic restorative treatment (ART) in different storage periods. Material and Methods: Specimens were divided according to the GIC ( $n=12)$ : IZ - Ion-Z, KM - Ketac Molar Easymix, RS - Riva Self Cure, and GL - Gold Label 9. They were prepared and stored in distilled water. Superficial microhardness (SMH) was evaluated (KHN) in three phases: (A) after 1, (B) 3, and (C) 7 days of storage. Data were submitted to 2 -way ANOVA and Tukey tests $(\alpha=5 \%)$. Results: The average KHN values for phases A, B, and C were, respectively, 33.05 \pm 9.74; $33.21 \pm 10.31$ and $52.07 \pm 11.75$ (IZ); $50.35 \pm 11.39$; $66.05 \pm 10.48$ and $67.77 \pm 13.80(\mathrm{KM}) ; 89.63 \pm 15.59 ; 71.31 \pm 23.86$ and $57.70 \pm 16.89$ (RS); $42.18 \pm 9.03$; $68.54 \pm 6.83$ and $57.95 \pm 8.24$ (GL). Significant differences were observed: GIC, time, and interaction of both $(\mathrm{p}<0.05)$. KHN values differed between the groups, except in the GIC parameter for KM and GL. The time parameter values of phase A were lower than those of B and C, except for IZ and RS. Conclusion: The initial mechanical stabilization differed between the types of GIC tested and the storage time, and after the final period, all had similar SMH.
\end{abstract}

Keywords: Dental Cements; Glass Ionomer Cements; Hardness Tests; Zinc. 


\section{Introduction}

Atraumatic restorative treatment (ART) is a minimally invasive technique, allowing for the maintenance of a sound dental structure through the selective removal of caries (softened dentine) with manual instruments. It also allows for the immediate restoration of cavity preparation, involving glass ionomer cement (GIC) of high viscosity, which takes advantage of its physical-chemical characteristics, manual handling, adhesive capacity, and fluoride release power that acts as an antibacterial agent [1,2]. This treatment modality reduces the number of pulp exposures, which reduces the number of endodontics and extractions, leading to less stress and anxiety for the patient since it rarely causes pain. Additionally, it does not require the use of anesthesia, rotatory instruments, or rubber dam isolation [3]. Thus, it is an economical and effective method to prevent and control caries disease in vulnerable populations [4,5].

The biggest problem with GIC is related to its maturation time due to the fact that the last phase of the material setting process is very slow, lasting more than 24 hours, as well as the extremely slow release of aluminum ions from the glass powder. This maturation is clinically related to the hardening of the material, and because it is not fully hardened, the first 24 hours after the application of this material becomes critical [3]. The GIC is susceptible to hygroscopic changes in the environment and may suffer syneresis and imbibition processes, which are the loss and gain of water to the external environment, respectively. Thus, there is a high potential for solubility with its mechanical properties and not reaching a satisfactory standard [6]. Thus, a seal of this cement is indicated right after its insertion in the oral environment, which is extremely humid, which can be carried out with cavity varnish, dental adhesives, Vaseline, or even colorless nail polish $[7]$.

ART has been performed by professionals who are unaware of the technique or have used it in contraindicated cavities, or even with inadequate GICs [8]. GICs adhere well to the tooth structure, but fail in the mechanical properties of the material itself [9], such as compressive strength (CS), flexural strength (FS), diametrical tensile strength (DTS), fracture toughness (FT), Knoop microhardness (KHN) or Vickers (VHN), wear rate (WR), fatigue, and creep [6].

Although GIC is not a resistant material under areas of great masticatory effort [10], many attempts to improve its mechanical properties are reported in the literature. These aim to improve these materials' physical properties to use them in the posterior region with the ART technique [11]. Some of these studies attempted including zirconia hydroxyapatite inserts/particles [12], carbon nanotubes [13,14], titanium dioxide [15], and casein phosphopeptide-amorphous calcium phosphate [16]. They also tried using auxiliary methods of accelerating the setting reaction (ultrasound, heating, halogen light, and LED) [17,18] and adding zinc oxide $(\mathrm{ZnO})$ nanoparticles [19]. These new materials are expensive in the Brazilian market, and national companies have been launching materials to meet these new needs.

$\mathrm{ZnO}$ is a compound that has been used in the form of nanoparticles in dental materials, in addition to being biocompatible and non-toxic in small concentrations [20,21]. It is believed that $\mathrm{ZnO}$ nanoparticles inhibit the growth of various microorganisms [22] due to the ability to change the components of the bacterial cell membrane, causing the loss of intracellular material and, consequently, cell death [23,24]. In previous studies, experimental GICs that were $\mathrm{ZnO}$-based showed great potential for biomedical application. However, the mechanical properties were lower than conventional GICs that are based on aluminum silicate [25-27]. Although $\mathrm{ZnO}$ nanoparticles have antibacterial potential at low concentrations (0.02\% to 5\%) without affecting biocompatibility and physical and mechanical properties [21,28], studies that associate $\mathrm{ZnO}$ nanoparticles with GICs have been explored in the scientific literature [29-31]. 
In the Brazilian market, there is a GIC that is reinforced with self-curing zinc (Ion-Z, FGM, Joinville, SC, Brazil) with active bactericidal and dentinogenic ingredients, aiming at the control of caries disease. According to the manufacturer, the main characteristics involve high bactericidal capacity, release of fluoride ions, high mechanical resistance, high chemical adhesion to enamel and dentin, fast setting reaction, excellent viscosity and biocompatibility, less curing contraction, and high smoothness. The manufacturer recommends its use for temporary restorations in permanent teeth, as a base for permanent restorations, in non-carious cervical lesions, restorations in primary teeth, and the ART technique. It is worth mentioning that, to date, the literature evaluating the properties of this new material with bioactive properties is scarce [18,32,33].

Even though GICs have improved properties in the long-term, it is essential to understand how long it takes for these materials to stabilize mechanically since maturation does not happen immediately after handling [2,8]. This knowledge is important to support possible restorations failures (dissolution and fractures) and / or adhesives that occur with restorations made with these materials. Thus, this study is necessary to verify whether these improvements of the mechanical properties of GICs using zinc particles are indicated for ART.

The aim of this study was to determine the initial mechanical stabilization of different GICs used in the ART technique, determined by analyzing their surface hardness in different periods of storage in distilled water. The null hypotheses were that the surface microhardness of the studied GICs (including the zinc modified GIC) do not differ between them and that the analyzed times do not interfere in this property either.

\section{Material and Methods}

Pilot Study

To determine the ideal powder-liquid proportion for each type of GIC tested in the study, 10 repetitions of the powder and liquid were performed as indicated by the manufacturer and the respective weighing on an analytical precision balance (Shimadzu, Japan). Following this, the mean and standard deviation values for the powder and liquid were obtained. To provide a standardized measurement, the powder-liquid proportions shown in Table 1 were followed.

Table 1. Proportion of powder and liquid for the different types of GIC.

\begin{tabular}{lc}
\multicolumn{1}{c}{ GIC } & Powder-Liquid \\
\hline Ion-Z (FGM) & $1.45: 1.00$ \\
Ketac Molar Easymix (3M/ESPE) & $3.88: 1.00$ \\
Riva Self Cure (SDI) & $2.87: 1.00$ \\
Gold Label 9 (GC) & $3.67: 1.00$ \\
\hline
\end{tabular}

Six cylindrical specimens (5 $\mathrm{mm}$ in diameter and 4-mm thick) of each type of GIC were also made to carry out the pilot study after 24 hours (1 day) and 72 hours (3 days) of storage in distilled water. The data from the pilot test are shown in Table 2 . The data from this pilot study were used for the sample calculations of the study in question.

Table 2. Surface microhardness mean values for different GIC and storage periods pilot test. Values in KHN.

\begin{tabular}{lcc}
\multicolumn{1}{c}{ GIC } & After 1 Day & After 3 Days \\
\hline Ion-Z (FGM) & $39.05 \pm 13.85$ & $184.62 \pm 71.38$ \\
Ketac Molar Easymix (3M/ESPE) & $116.59 \pm 36.29$ & $119.08 \pm 35.33$ \\
Riva Self Cure (SDI) & $68.48 \pm 18.06$ & $94.47 \pm 21.87$ \\
Gold Label 9 (GC) & $75.21 \pm 20.70$ & $108.16 \pm 23.30$ \\
\hline
\end{tabular}


Materials and Samples

Four types of GICs indicated for the ART treatment were tested: Ion-Z (FGM, Joinville, SC, Brazil); Ketac Molar Easymix (3M / ESPE, St. Paul, Minnesota, USA); Riva Self Cure (SDI Limited, Victoria, Australia) and Gold Label 9 (GC Dental Corporation, Tokyo, Japan). From the data obtained with the pilot test (mean and standard deviation), the sample calculation was performed ( $\mathrm{G} *$ Power 3 for Mac). The following parameters were used: test power at $80 \%$, number of groups to be tested equal to four, probability error at 0.05 and effect size (f) equal to 1.255815 (determined using pilot data), and the sample calculations of 12 specimens per group.

\section{Specimen Preparation}

For the preparation of the specimens, the powder and liquid mass of the GIC was initially determined using an analytical precision balance (Shimadzu Corp., Kyoto, Japan) to standardize the relative proportions of the GIC components [14].

The GICs were manipulated according to the manufacturer's recommendations on a pad of paper and using a plastic spatula. The manipulated GIC was inserted with the aid of a Centrix syringe in plastic molds to make specimens with equal proportions, i.e., $4 \mathrm{~mm}$ in thickness and $5 \mathrm{~mm}$ in diameter. The pressure was then applied with a polyester matrix and glass slide onto the specimen surfaces to promote straight and smooth surfaces. The exposed surfaces were then protected with Vaseline [14].

After the initial setting reaction (10 to 15 minutes), the specimens that were protected with Vaseline and kept in containers containing distilled water at $37^{\circ} \mathrm{C}$ for 1,3 , and 7 days were removed from the plastic mold. After this period, the specimens were fixed with sticky wax on acrylic resin blocks and their surfaces were polished using a circular polishing machine (EcoMet / AutoMet 250, Buehler Ltd. Lake Bluff, IL, USA) with P400o sandpaper (Extec Corp, Enfield, CT, USA) [14].

\section{Surface Microhardness}

The specimens were subjected to a superficial hardness analysis using a Knoop indenter in a digital microdurometer (HMV-2, Shimadzu Corp., Kyoto, Japan) using a force of $25 \mathrm{~g}$ and an indentation time of 30 seconds. Five measurements were made on the surface of each specimen, spaced $100 \mu \mathrm{m}$ apart, and the means of these were used for the results [14]. The data obtained were recorded in a KHN unit in three phases: (A) after 1, (B) 3, and (C) 7 days of storage in distilled water.

\section{Data Analysis}

The data were tabulated and analyzed using MedCalc for Windows software (version 17.2). In this study, a two-way repeated measures ANOVA test was used, with the type of GIC used (four groups) and the storage time in distilled water (3 phases) as the variables. The Tukey test was used to detect differences between the groups. A p-value $<0.05$ was considered statistically significant.

\section{Results}

Table 3 and Figure 1 show the mean values and standard deviation of the microhardness determined in the different types of GICs after 1 day, 3 days, and 7 days of storage in distilled water. The ANOVA test detected statistically significant differences for the following parameters: type of GIC $(p<0.001)$, storage time in water $(p=0.0141)$ and the interaction between both of these $(p<0.001)$. The Tukey post-test found that the 
KHN values differed between the groups, except for in the Ketac Molar and Gold Label 9 GICs. The microhardness values after 1 day of storage were lower than after 3 and 7 days of storage in terms of time parameters, except for the Ion-Z group ( 1 day $=3$ days $<7$ days) and Riva Self-Cure GICs $(1$ day $>3$ days $=7$ days) $(\mathrm{p}<0.05)$.

Table 3. Mean and standard deviation of superficial microhardness values (KHN) considering the factors: types of GIC and the storage time in distilled water for 1, 3, and 7 days.

\begin{tabular}{|c|c|c|c|}
\hline GIC & After 1 Day & After 3 Days & After 7 Days \\
\hline Ion-Z (FGM) & $33.05 \pm 9.74 \mathrm{~A}, \mathrm{a}$ & $33.21 \pm 10.31 \mathrm{~A}, \mathrm{a}$ & $52.07 \pm 11.75 \mathrm{~A}, \mathrm{~b}$ \\
\hline Ketac Molar Easymix (3M/ESPE) & $50.35 \pm 11.39 \mathrm{~A}, \mathrm{a}$ & $66.05 \pm 10.48^{\mathrm{B}, \mathrm{b}}$ & $67.77 \pm 13.80 \mathrm{~A}, \mathrm{~b}$ \\
\hline Riva Self Cure (SDI) & $89.63 \pm 15.59$ B,a & $71.31 \pm 23.86$ В,b & $57.70 \pm 16.89 \mathrm{~A}, \mathrm{~b}$ \\
\hline Gold Label 9 (GC) & $42.18 \pm 9.03 \mathrm{~A}, \mathrm{a}$ & $68.54 \pm 6.83 \mathrm{~B}, \mathrm{~b}$ & $57.95 \pm 8.24 \mathrm{~A}, \mathrm{~b}$ \\
\hline
\end{tabular}

ANOVA test \& Tukey post-test; Capital letters represent statistical differences in the columns (within each time); Lower case letters represent statistical differences in the lines (within each GIC).

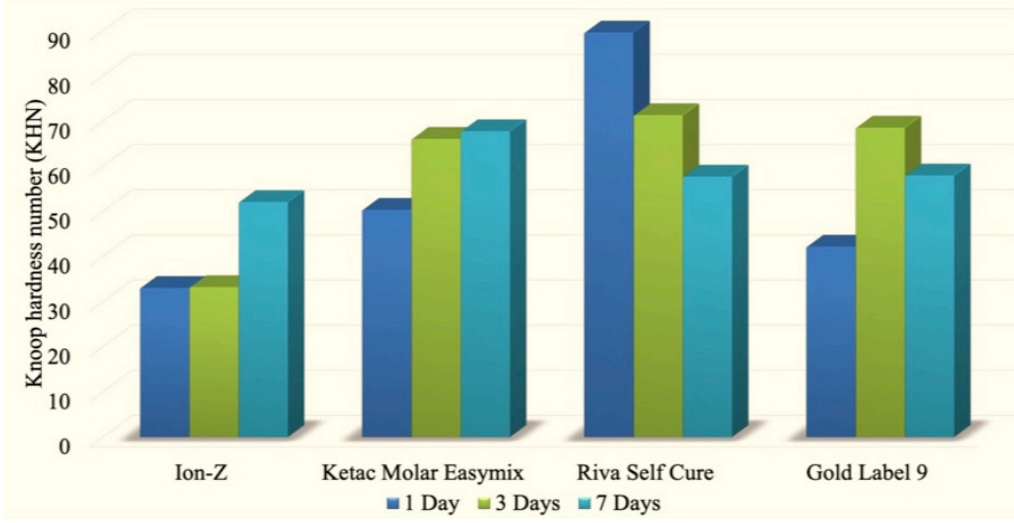

Figure 1. Mean values of surface microhardness (KHN) considering the factors: types of GIC and the storage time in distilled water for 1,3 , and 7 days.

\section{Discussion}

Dental caries still has a large impact on children's health; ART is considered a strategy based on health promotion that promotes an improvement in quality of life, using GIC materials that allow adherence to dental structures and the release of fluorides. Although classic GIC is the material of choice in several procedures in dentistry, some of its properties are still not entirely satisfactory [34].

In this context, it is important to understand the maturation time that these materials require to stabilize mechanically since this does not happen immediately after manipulation [8] and may still be related to early restoration failures. It is known that materials with good microhardness values indicate ease of finishing, polishing, good resistance to use, with less formation of scratches or grooves, which makes it difficult to form dental biofilm, resulting in less risk of compromising its resistance to fatigue and esthetic failures [9].

Based on the literature's information, this study was necessary to verify which relative improvements in the mechanical properties of different GICs were indicated for ART, including GIC reinforced by zinc particles. It is known that the incorporation of several types of nanoparticles in GICs increases the physicalmechanical and antimicrobial properties of these materials [11]. However, in regards to GIC Ion-Z properties, the literature is still scarce with regard to its antimicrobial properties, anti-caries effect, external sources in the maturation process, and the handling/proportion of powder and liquid and its effects on surface roughness $[18,32,33]$, which makes it difficult to compare this GIC type with previous studies regarding surface microhardness data. 
In the present study, the two null hypotheses were rejected because when comparing the type of GIC factors, storage time in distilled water, and the interaction between them, statistically significant differences were observed $(\mathrm{p}<0.05)$, corroborating the hypothesis that some materials increased their initial mechanical stabilization after their relative storage times in distilled water (Ion-Z, Ketac Molar Easymix and Gold Label 9). However, the Riva Self Cure's surface microhardness decreased over time. It should be noted that at the end of 7 days, all types of GICs showed similar surface microhardness values. We suggest that some factors, such as the GIC composition and the powder/liquid proportion [35], may have influenced these results.

The ART technique aims to reduce costs, so the dentist must relate the costs and benefits to decide which material should be used. As already demonstrated in previous studies, and as the gold standard of treatment, with proven effectiveness [12,14], the Ketac Molar Easymix has a high cost in the Brazilian market. This makes the implementation of the ART technique using this material in the public service unfeasible.

Ion-Z, more recently introduced in the Brazilian market, has the addition of zinc particles in its composition; however, it did not present a significant microhardness in its first 72 hours of maturation. However, at the end of 7 days, its microhardness increased significantly, becoming an option for ART, as long as the syneresis and imbibition phase of the material can be controlled. A study that was carried out to test the addition of $5 \%$ of $\mathrm{ZnO}$ nanoparticles to the conventional restorative GIC observed a decrease of about $10 \%$ in its superficial microhardness, with no changes in its flexural strength compared to the GIC without this addition [31].

In a previous study, the Ion-Z GIC showed less roughness when the proportion of powder and liquid was $1: 1[33]$. In the present study, methodological care was taken to standardize the proportion of powder and liquid for the manipulation of the different GICs. It is known that the concentration of zinc nanoparticles present in the GIC can increase its mechanical resistance and chemical adhesion, improving hypomineralization $[30]$.

According to the analyzed data, noted that Gold Label 9 was the one that came closest to the microhardness values presented by the gold standard Ketac Molar Easymix in all analyzed periods. Riva Self Cure showed the highest initial surface microhardness value after 1 day of storage and suffered a drop in its surface microhardness over the other follow-up days. However, after 7 days, it remained similar to the others. In a previous study, low Knoop surface microhardness values were observed for Riva Self Cure compared to Ketac Molar Easymix after 1 day of paraffin storage [36].

In the present study, the lack of simulated aging through thermocycling might not be considered a limitation because the influence of thermocycling on tooth-colored materials and GICs hardening is still controversial $[37,38]$. Moreover, laboratorial studies are limited to draw real clinical considerations.

According to all the items analyzed (time, material and interaction between them), it is suggested that the best material to be used in the ART technique is: Ketac Molar Easymix> Gold Label 9> Riva Self Cure> Ion-Z. Thus, new long-term follow-up clinical studies are necessary to elucidate the different glass ionomer cements' maturation.

\section{Conclusion}

The initial mechanical stabilization differs between the different types of GICs tested in different storage periods in distilled water. The surface microhardness of GICs reinforced with zinc particles is similar to that of standard GICs for ART after 7 days of storage. 


\section{Authors' Contributions}

\begin{tabular}{|c|c|c|}
\hline CSR & (D) https://orcid.org/0000-0002-3746-551X & $\begin{array}{l}\text { Formal Analysis, Investigation, Resources, Data Curation, Writing - Original Draft and Writing } \\
\text { - Review and Editing. }\end{array}$ \\
\hline MMP & https://orcid.org/0000-0002-2268-764.6 & Investigation, Data Curation and Writing - Original Draft. \\
\hline PLBS & https://orcid.org/0000-0002-6674-6142 & Investigation, Data Curation and Writing - Original Draft. \\
\hline ROG & https://orcid.org/0000-0001-5749-0651 & $\begin{array}{l}\text { Conceptualization, Data Curation, Writing - Original Draft, Writing - Review and Editing and } \\
\text { Visualization. }\end{array}$ \\
\hline $\mathrm{EB}$ & https://orcid.org/0000-0001-9299-8792 & $\begin{array}{l}\text { Conceptualization, Methodology, Resources, Data Curation, Writing - Original Draft, Writing - } \\
\text { Review and Editing and Visualization. }\end{array}$ \\
\hline MBD & (D) https://orcid.org/0000-0002-0693-2162 & $\begin{array}{l}\text { Conceptualization, Methodology, Formal Analysis, Data Curation, Writing - Original Draft, } \\
\text { Writing - Review and Editing, Visualization, Supervision and Project Administration. }\end{array}$ \\
\hline
\end{tabular}

\section{Financial Support}

None.

\section{Conflict of Interest}

The authors declare no conflicts of interest.

\section{Data Availability}

The data used to support the findings of this study can be made available upon request to the corresponding author.

\section{References}

[1] Frencken JE, Pilot T, Songpaisan Y, Phantumvanit P. Atraumatic restorative treatment (ART): rationale, technique, and development. J Public Health Dent 1996; 56(3 Spec No):135-40.

https://doi.org/10.1111/j.1752-7325.1996.tbo2423.x

[2] Holmgren CJ, Roux D, Doméjean S. Minimal intervention dentistry: part 5. Atraumatic restorative treatment (ART) - a minimum intervention and minimally invasive approach for the management of dental caries. Br Dent $\mathrm{J} 2013$; 214(1):11-8. https://doi.org/ 10.1038/sj.bdj.2012.1175

[3] Yip HK, Smales RJ, Ngo HC, Tay FR, Chu FC. Selection of restorative materials for the atraumatic restorative treatment (ART) approach: a review. Spec Care Dentist 2001; 21(6):216-21.

https://doi.org/10.1111/j.1754-4505.2001.tbo0257.x

[4] Frencken JE, Makoni F, Sithole WD. ART restorations and glass ionomer sealants in Zimbabwe: survival after 3 years. Community Dent Oral Epidemiol 1998; 26(6):372-81. https://doi.org/10.1111/j.1600-0528.1998.tbo1975.x

[5] Frencken JE, Leal SC. The correct use of the ART Approach. J Appl Oral Sci 2010; 18(1):1-4. https://doi.org/10.1590/s1678-77572010000100002

[6] Xie D, Brantley WA, Culbertson BM, Wang G. Mechanical properties microstructures glass-ionomer cements. Dent Mater 2000; 16(2):129-38. https://doi.org/10.1016/s0109-5641(99)00093-7

[7] Mount GJ. Clinical performance of glass-ionomers. Biomaterials 1998; 19(6):573-9. https://doi.org/10.1016/s0142-9612(97)O0139-7

[8] Bresciani E. Clinical trials with Atraumatic Restorative Treatment (ART) in deciduous and permanent teeth. J Appl Oral Sci 2006; 14(Special Issue):14-9. https://doi.org/10.1590/S1678-77572006000700004

[9] Dowling AH, Stamboulis A, Fleming GJ. The influence of montmorillonite clay reinforcement on the performance of a glass ionomer restorative. J Dent 2006; 34(10):802-10. https://doi.org/10.1016/j.jdent.2006.03.005

[10] Kleverlaan CJ, van Diunen RN, Feilzer AJ. Mechanical properties of glass ionomer cements affected by curing methods. Dent Mater 2004; 2O(1):45-50. https://doi.org/10.1016/s0109-5641(03)00067-8

[11] Moheet IA, Luddin N, Rahman IA, Kannan TP, Nik Abd Ghani NR, Masudi SM. Modifications of glass ionomer cement powder by addition of recently fabricated nano-fillers and their effect on the properties: a review. Eur $\mathrm{J}$ Dent 2019; 13(3):470-7. https://doi.org/10.1055/s-0039-1693524

[12] Gu YW, Yap AU, Cheang P, Khor KA. Effects of incorporation of $\mathrm{HA} / \mathrm{ZrO}(2)$ into glass ionomer cement (GIC). Biomaterials 2005; 26(7):713-20. https://doi.org/10.1016/j.biomaterials.2004.03.019

[13] Akasaka T, Watari F, Sato Y, Tohji K. Apatite formation on carbon nanotubes. Mater Sci Eng C 2006; $26(4): 675-8$. https://doi.org/10.1016/j.msec.2005.03.009

[14] Santos MMPR, Mathias IF, Diniz MB, Bresciani E. Evaluation of surface hardness of glass ionomer reinforced cements by carbon nanotubes. Rev Odontol UNESP 2015; 44(2):108-12. https://doi.org/10.1590/1807-2577.1060

[15] Elsaka SE, Hamouda IM, Swain MV. Titanium dioxide nanoparticles addition to a conventional glass-ionomer restorative: influence oh physical and antibacterial properties. J Dent 2011; 39(9):589-98. https://doi.org/10.1016/j.jdent.2011.05.006 
[16] Al Zraikat H, Palamara JE, Messer HH, Burrow MF, Reynolds EC. The incorporation of casein phosphopeptideamorphous calcium phosphate into a glass ionomer cement. Dent Mater 2011; 27(3):235-43. https://doi.org/10.1016/j.dental.2010.10.008

[17] Yap AU, Pek YS, Kumar RA, Cheang P, Khor KA. Experimental studies on a new bioactive material: HAIonomer cements. Biomaterials 2002; 23(3):955-62. https://doi.org/10.1016/s0142-9612(01)00208-3

[18] de Oliveira BMB, Agostini IE, Baesso ML, Menezes-Silva R, Borges AFS, Navarro MFL, et al. Influence of external energy sources on the dynamic setting process of glass-ionomer cements. Dent Mater 2019; 35(3):450-6. https://doi.org/10.1016/j.dental.2019.01.003

[19] Agarwal P, Nayak R, Upadhya N, Ginjupalli K, Gupta L. Evaluation of properties of glass ionomer cements reinforced with zinc oxide nanoparticles - an in vitro study. Mater Today: Proceed 2018; 5(8):16065-72. https://doi.org/10.1016/j.matpr.2018.05.088

[20] Huang Z, Zheng X, Yan D, Yin G, Liao X, Kang Y, et al. Toxicological effect of ZnO nanoparticles based on bacteria. Langmuir 2008; 24(8):4140-4. https://doi.org/10.1021/la7035949

[21] Kasraei S, Sami L, Hendi S, Alikhani MY, Rezaei-Soufi L, Khamverdi Z. Antibacterial properties of composite resins incorporating silver and zinc oxide nanoparticles on Streptococcus mutans and Lactobacillus. Restor Dent Endod 2014; 39(2):109-14. https://doi.org/10.5395/rde.2014.39.2.109

[22] Hajipour MJ, Fromm KM, Ashkarran AA, Jimenez de Aberasturi D, de Larramendi IR, Rojo T, et al. Antibacterial properties of nanoparticles. Trends Biotechnol 2012; 30(10):499-511. https://doi.org/10.1016/j.tibtech.2012.06.004

[23] Liu Y, He L, Mustapha A, Li H, Hu ZQ, Lin M. Antibacterial activities of zinc oxide nanoparticles against Escherichia coli O157:H7. J Appl Microbiol 2009; 107(4):1193-1201.

https://doi.org/10.1111/j.1365-2672.2009.04303.x

[24] Melo MA, Guedes SF, Xu HH, Rodrigues LK. Nanotechnology-based restorative materials for dental caries management. Trends Biotechnol 2013; 31(8):459-67. https://doi.org/10.1016/j.tibtech.2013.05.010

[25] Boyd D, Towler MR. The processing, mechanical properties and bioactivity of zinc based glass ionomer cements. J Mater Sci Mater Med 2005; 16(9):843-50. https://doi.org/10.1007/s10856-005-3578-1

[26] Brauer DS, Gentleman E, Farrar DF, Stevens MM, Hill RG. Benefits and drawbacks of zinc in glass ionomer bone cements. Biomed Mater 2011; 6(4):045007. https://doi.org/10.1088/1748-6041/6/4/04500

[27] Kim DA, Abo-Mosallam HA, Lee HY, Kim GR, Kim HW, Lee HH. Development of a novel aluminum-free glass ionomer cement based on magnesium/strontium-silicate glasses. Mater Sci Eng C Mater Biol Appl 2014; 42:665-71. https://doi.org/10.1016/j.msec.2014.06.006

[28] Tavassoli Hojati S, Alaghemand H, Hamze F, Ahmadian Babaki F, Rajab-Nia R, Rezvani MB, et al. Antibacterial, physical and mechanical properties of flowable resin composites containing zinc oxide nanoparticles. Dent Mater 2013; 29(5):495-505. https://doi.org/10.1016/j.dental.2013.03.011

[29] Spencer CG, Campbell PM, Buschang PH, Cai J, Honeyman AL. Antimicrobial effects of zinc oxide in an orthodontic bonding agent. Angle Orthod 2009; 79(2):317-22. https://doi.org/10.2319/011408-19.1

[30] Garcia PPNS, Cardia MFB, Francisconi RS, Dovigo LN, Spolidório DMP, de Souza Rastelli AN, et al. Antibacterial activity of glass ionomer cement modified by zinc oxide nanoparticles. Micros Res Tech 2017; 80(5):456-61. https://doi.org/10.1002/jemt.22814

[31] Panahandeh N, Torabzadeh H, Aghaee M, Hasani E, Safa S. Effect of incorporation of zinc oxide nanoparticles on mechanical properties of conventional glass ionomer. J Conserv Dent 2018; 21(2):130-5. https://doi.org/10.4103/JCD.JCD_170_17

[32] Souza EBM, Santos DMS, Magalhães AC. Antimicrobial and anti-caries effect of new glass ionomer cement on enamel under microcosm biofilm model. Braz Dent J 2018; 29(6):599-605. https://doi.org/10.1590/0103-6440201802163

[33] Machado KDS, Reges RV, Botelho TL, Santos FG. Efeito da manipulação e proporção pó e líquido do cimento de ionômero de vidro reforçado com zinco na rugosidade superficial (Parte 1). Rev Cienc Odontol 2019; 3(1):20-4.

[34] Bansal R, Burgess J, Lawson NC. Wear of an enhanced resin-modified glass-ionomer restorative material. Am J Dent 2016; 29(3):171-4.

[35] Shiozawa M, Takahashi H, Iwasaki N. Fluoride release and mechanical properties after 1-year water storage of recent restorative glass ionomer cements. Clin Oral Invest 2014; 18(4):1053-60. https://doi.org/10.1007/s00784-013-1074-4.

[36] Bonifácio CC, Kleverlaan CJ, Raggio DP, Werner A, Carvalho RCR, van Amerongen WE. Physical-mechanical properties of glass ionomer cement indicated for atraumatic restorative treatment. Austr Dent J 2009; 54(3):233-7. https://doi.org/10.1111/j.1834-7819.2009.01125.x

[37] Yap AU, Wee KE, Teoh SH. Effects of cyclic temperature changes on hardness of composite restoratives. Oper Dent 2002; 27(1):25-9

[38] Yap AU, Wang X, Wu X, Chung SM. Comparative hardness and modulus of tooth-colored restoratives: a depth$\begin{array}{llll}\text { sensing microindentation } & \text { Biomaterials }\end{array}$ https://doi.org/10.1016/j.biomaterials.2003.09.003 